\title{
Social capital and consumer happiness: toward an alternative explanation of consumer-brand identification
}

\author{
Masayuki Yoshida $^{1}$ (1) $\cdot$ Brian S. Gordon ${ }^{2} \cdot$ Jeffrey D. James ${ }^{3}$
}

Revised: 11 May 2021 / Accepted: 18 May 2021 / Published online: 7 June 2021

(c) The Author(s), under exclusive licence to Springer Nature Limited 2021

\begin{abstract}
The purposes of this study are to integrate organizational social capital theory and consumer happiness in a prior brand identification model and test the antecedents and consequences of consumer-brand identification over time. In the context of professional football, we collected data from 374 panel registrants of an online research service firm throughout a season. The results indicated consumer-brand identification was impacted to a greater extent by two social capital factors: (1) social interaction ties and (2) shared vision, than by brand prestige and brand distinctiveness. Both social interaction ties and consumer-brand identification were also predictive of future behavioral loyalty and purchase frequency. Further, our moderation analysis revealed the impact of consumer-brand identification on behavioral loyalty was contingent on consumer happiness. The proposed framework and results reinforce the importance of consumer-to-consumer social capital and consumer happiness and add new insights into the dynamics of consumer-brand identification, consumer happiness, and enduring consumer loyalty.
\end{abstract}

Keywords Social capital · Consumer happiness $\cdot$ Consumer-brand identification · Organizational identification · Consumer loyalty

\section{Introduction}

Building a deep and meaningful relationship between a consumer and a brand contributes to the long-term success and welfare of companies (Bhattacharya and Sen 2003). Over the last decade, consumer-brand identification (CBI) has emerged as an important construct that explains a consumer's sense of belonging to a brand and positively influences consumer loyalty (Haumann et al. 2014; Lam et al. 2010; Popp and Woratschek 2017; Stokburger-Sauer et al.

Masayuki Yoshida

masayoshida@hosei.ac.jp

Brian S. Gordon

bsgordon@ku.edu

Jeffrey D. James

jdjames@fsu.edu

1 Department of Sports and Health Studies, Hosei University, 4342 Aihara, Machida, Tokyo 194-0298, Japan

2 University of Kansas, 146C-1 Robinson Center, 1301 Sunnyside Avenue, Lawrence, KS 66045-7567, USA

3 Florida State University, 139 Chieftan Way, Tully 1002, Tallahassee, FL 32306-4280, USA
2014). To date, scholars have established the sequential relationships between brand characteristics (e.g., prestige and distinctiveness), CBI, and consumer loyalty (Carlson et al. 2009; Stokburger-Sauer et al. 2014).

While the primary focus of CBI is on the vertical tie between a consumer and a brand, the horizontal ties between fellow brand users also exist and have been examined in the literature on brand community (Muniz and O'Guinn 2001) and consumer-to-consumer social capital (Mathwick et al. 2007). In the customer-based brand equity pyramid, Keller (2008) identifies sense of community as a dimension of brand resonance which is considered "the ultimate relationship and level of identification that the customer has with the brand" (p. 72). This view is consistent with selfdetermination theory (Ryan and Deci 2000) which includes the premise that a sense of community is associated with the basic human needs of autonomy, competence, and relatedness, which in turn foster intrinsic motivation and wellbeing. These theoretical perspectives together imply that CBI not only stems from brand characteristics (e.g., brand prestige and brand distinctiveness), but also entails a consumer's sense of belonging to the brand as a social unit. In this study, we emphasize the importance of social capital 
among consumers, rather than prestigious and distinctive brand characteristics.

Another research void involves the role of consumer happiness in CBI research. Creating brands that make consumers happy is an effective marketing strategy because it produces a strong feeling of affective commitment and brand loyalty (Pansari and Kumar 2017; Schnebelen and Bruhn 2018). Consumer happiness is defined as a state of wellbeing related to a specific consumption activity (Mogilner et al. 2012; van Boven and Gilovich 2003) and can be seen as a useful comprehensive construct for explaining a sense of the larger picture of how brand consumption leads to people experiencing a happy life over time (Nicolao et al. 2009). Scholars have completed preliminary work exploring how consumer happiness contributes to a brand's long-term success (Devezer et al. 2014; Zhong and Mitchell 2013), providing an opportunity to further advance our understanding of the effect of consumer happiness on CBI.

It is also important to note that most findings in previous CBI research are based on cross-sectional data collected at a single point in time and arise from the relationship between CBI and behavioral intentions (Lin et al. 2019; Millán and Díaz 2014; Popp and Woratschek 2017; Stokburger-Sauer et al. 2014; Wolter and Cronin 2016). Although a few researchers tested the dynamic changes of antecedents (e.g., perceived quality, self-brand congruity, and consumer innovativeness) and outcomes (e.g., behavioral intentions and willingness to pay more) of CBI over time (Haumann et al. 2014; Huang et al. 2017; Lam et al. 2013), it is still not clear how CBI influences future behavioral consequences, for example, in relation to behavioral loyalty (Garnefeld et al. 2013; Zeithaml et al. 1996) and purchase frequency (Seiders et al. 2005). Conducting a longitudinal study also allows us to examine the interaction effect of CBI and consumer happiness on future behavioral consequences. This analysis is important because consumer happiness is relatively stable and enduring (Devezer et al. 2014) and would be related to long-term brand consumption in people's life (Zhong and Mitchell 2013).

Recognizing there is much left to understand, a more comprehensive model integrating CBI, social capital, consumer happiness, and future behavioral outcomes is warranted. The purposes of this study are to (1) develop a model that expands the traditional organizational identification framework (Ashforth and Mael 1989; Mael and Ashforth 1992) with the inclusion of organizational social capital (Nahapiet and Ghoshal 1998; Tsai and Ghoshal 1998) and consumer happiness (van Boven and Gilovich 2003) and (2) investigate the antecedents and consequences of $\mathrm{CBI}$ over time.

This study falls within the paradigm of transformative consumer research (TCR), a body of scholarship concerned with linking consumer research to consumer well-being
(Anderson et al. 2013; Csikszentmihalyi 2000; Mick 2006). In the current marketplace which serves as a highly complicated, uncertain, and competitive environment, consumers are not likely to remain loyal to brands without achieving happiness in life. In fact, in the face of economic disturbances, brands such as Coca-Cola and McDonald's attempt to connect with consumers by promising happiness with simple, but fundamental messages (e.g., "open happiness" and "happy meal"; Mogilner et al. 2012). This can also be achieved by appealing to consumer happiness through extraordinary experiences as evidenced by brands such as Disney and BMW (Bhattacharjee and Mogilner 2014). An integration of CBI and consumer happiness is both timely and practical.

The remaining content of this paper is organized as follows: first, an integrative framework of CBI, consumer-toconsumer social capital, and consumer happiness is proposed in order to identify the antecedents and consequences of CBI. The next section presents the methods we used. The results of hypothesis testing are then presented, followed by the discussion section.

\section{Theoretical model and hypotheses}

Organizational identification theory (Ashforth and Mael 1989; Mael and Asforth 1992) maintains that in order to identify with a brand, consumers need to perceive themselves as psychologically intertwined with the fate of a brand. In empirical work, researchers have used either Mael and Asforth's (1992) or Bergami and Bagozzi's (2000) cognitive identification scale to measure a person's perceived identification with a brand (Ahearne et al. 2005; Bhattacharya et al. 1995; Haumann et al. 2014). Consistent with this view, we follow the cognitive approach and define $\mathrm{CBI}$ as an individual's perceived oneness with a brand and the experience of the brand's successes and failures as one's own (Ashforth and Mael 1989; Stokburger-Sauer et al. 2014). In the following section, we first present research hypotheses regarding the relationships between social capital factors, CBI, and behavioral consequences. Then, research hypotheses pertaining to the relationships between $\mathrm{CBI}$, behavioral outcomes, and consumer happiness are derived (see Fig. 1).

\section{The impact of social capital}

According to organizational social capital theory (Nahapiet and Ghoshal 1998; Tsai and Ghoshal 1998), social capital is defined as "the sum of the actual and potential resources embedded within, available through, and derived from the network of relationships possessed by an individual or social unit" (Nahapiet and Ghoshal 1998, p. 243) and includes three dimensions: structural (e.g., social interaction ties), 
Fig. 1 Theoretical framework and research hypotheses
Time 1 data: Collected in the first-half of the season
Time 2 data: Collected at

the end of the season

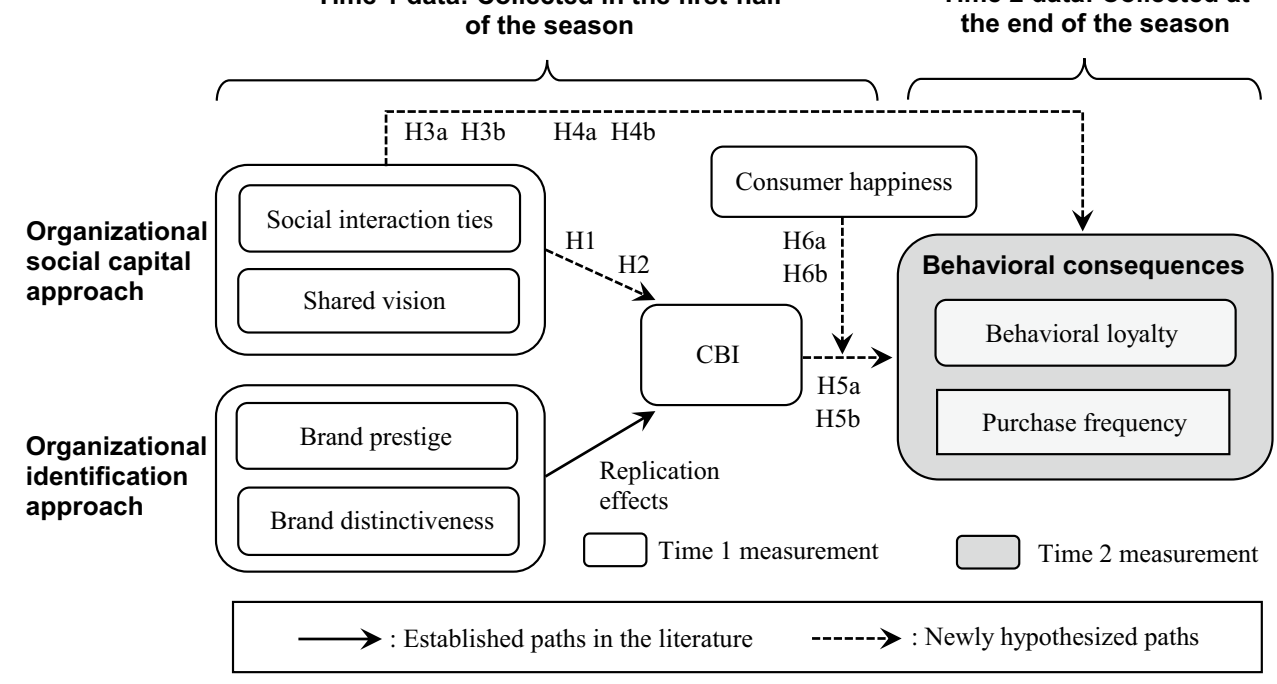

cognitive (e.g., shared vision and culture), and relational (e.g., trust, identification, and norms of reciprocity).

In this study, we attempt to extend CBI research by examining the impact of social interaction ties (structural dimension) and shared vision (cognitive dimension) on CBI (relational dimension). As a proxy variable of the relational dimension, we select social identification and exclude other relational characteristics (e.g., reciprocity and trust). Social identification is similar to the idea of bridging (or inclusive) social capital, which refers to a sense of connection with heterogeneous people (Putnam 2000) and represents CBI in brand communities. On the other hand, the elements of reciprocity and trust are related to the idea of bonding (or exclusive) social capital, which is a sense of cohesion or solidarity among homogeneous people (Putnam 2000). In brand communities, activating the feelings of reciprocity and trust is applicable only to those who are socialized into homogeneous networks of consumers. In order to adequately conceptualize relational social capital among heterogeneous brand community members, social identification should be taken into account.

In the current marketplace, "brands are shifting away from single to shared ownership" (p. 25, Swaminathan et al. 2020). On the basis of the literature reviewed, CBI may evolve from the social interactions among consumers. As consumers interact with one another over time, their relationship becomes more intimate and stable. Close and continuous social interactions allow consumers to know each other, share consumption experiences, and develop a common point of view (Tsai and Ghoshal 1998), thus increasing a sense of belongingness and identification with their brand community. Harmonious and enjoyable social interactions in brand communities play a key role in creating brand value (Mingione et al. 2020) and building CBI (Augusto and Torres 2018) because peer-to-peer communications in brand communities facilitate the sharing of brand-related information (Meek et al. 2019), value creation practices (Mingione et al. 2020; Schau et al. 2009), and the development of long-term relationships not only with other consumers, but also with the focal brand (Augusto and Torres 2018; Stokburger-Sauer et al. 2014). In a hyperconnected society, brands act as catalysts of social interactions among consumers that offer social benefits such as a sense of belonging and identity expression in brand communities (Swaminathan et al. 2020). Combining these considerations, we hypothesize the following:

H1 The social interaction ties among fellow brand users have a positive impact on CBI.

A shared vision and a set of common values may also stimulate the development of CBI. Organizational social capital theory maintains that common goals, values, and beliefs promote the harmony of social relationships and facilitate the value congruence between an organization and its members (Tsai and Ghoshal 1998). In marketing, corporate vision can shape corporate brand identity (Balmer 2012), and the sharing of common visions acts as a significant driver of value co-creation processes among actors (Mingione and Leoni 2020). In brand communities, shared visions lead consumers to have common brand meanings and co-produce communal brand identity (Healy and McDonagh 2013). An implication from these theoretical explanations is that cognitively shared visions and values may play a significant role in developing and maintaining the relationship between a consumer and a brand. That is, as a consumer has mutual goals and values with fellow brand users as well as an interdependent self-concept, greater identification with his or her favorite brand arises and promotes the assimilation of the person's self-concept into the image of the brand 
(Bagozzi and Dholakia 2006). Collectively, the pathway from shared vision to CBI can be hypothesized as follows:

H2 The shared vision among consumers in a brand community has a positive impact on CBI.

We also extend the brand management literature by examining the impact of consumer-to-consumer social capital on future behavioral loyalty. One way to explain this relationship is to assume that the more a consumer is integrated into a brand community, the more loyal the consumer is toward the brand (Muniz and O'Guinn 2001; Schau et al. 2009). The brand community literature offers explanations for this relationship. For example, previous researchers have found that consumers become loyal to their favorite brands by drawing values from peer-to-peer interactions in brand communities (Muniz and O'Guinn 2001; Schau et al. 2009). Consumers derive social and hedonic value from the consumption of branded offerings in brand communities (Schau et al. 2009). Such value-creating activities are socially constructed through consumer-to-consumer interactions and induce consumers to remain loyal to a brand as well as to the brand community (Muniz and O'Guinn 2001; Schau et al. 2009). Similarly, other researchers suggest that when consumers participate in and foster peer-to-peer interactions in a brand community, their brand involvement increases, thereby resulting in greater brand loyalty (Bagozzi and Dholakia 2006).

In this study we include two different types of behavioral loyalty: one assessing consumers' subjective intentions and one measuring purchase frequency. Previous studies have tested subjective measures of brand loyalty (e.g., Lin et al. 2019; Stokburger-Sauer et al. 2014; Wolter and Cronin 2016). To better understand and more consistently predict behavioral loyalty and determine if social capital and CBI influence long-term brand loyalty, we believe it is important to examine two loyalty constructs: subjective intentions and purchase frequency. Taken together, it is suggested that the social interaction ties among fellow brand users are likely to increase behavioral loyalty and purchase frequency. The reasoning described above prompts the following hypotheses:

H3a The social interaction ties among fellow brand users have a positive impact on behavioral loyalty.

H3b The social interaction ties among fellow brand users have a positive impact on purchase frequency.

We predict a shared vision among consumers is directly related to behavioral loyalty. In brand community research, scholars suggest that shared consciousness of kind, a way of thinking about things in brand communities, leads to a number of favorable behavioral consequences such as socializing, customizing, advocating, and expressing (Muniz and O'Guinn 2001; Schau et al. 2009). In order to engage in these brand community practices, consumers must develop the collective understanding and knowledge of value creation shared with other brand community members (Schau et al. 2009). This cognitive social capital is developed through communal consumption experiences in brand communities and imposes a strong sense of obligation or responsibility on consumers to purchase the same brand over time (Muniz and O'Guinn 2001; Schau et al. 2009). Oliver (1999) provides additional support by suggesting that due to the same consumption value and camaraderie shared among consumers in some social organizations (e.g., Harley-Davidson's Harley Owners' Group and Green Bay Packers' cheeseheads), they are willing to be socially integrated into the consumption village (e.g., brand community) that reinforces fully bonded brand loyalty. Combining these considerations leads to the following hypotheses:

H4a The shared vision among consumers in a brand community has a positive impact on behavioral loyalty.

H4b The shared vision among consumers in a brand community has a positive impact on purchase frequency.

\section{The impact of $\mathrm{CBI}$}

Behavioral loyalty refers to an individual's behavioral response to repurchase his or her favorite brand over time (Oliver 1999). According to organizational identification theory, consumers with high brand identification are more likely to return a favor to the brand and engage in various supportive behaviors than consumers with low brand identification (Mael and Ashforth 1992; Yoshida 2017). From the consumer's perspective, such behaviors include repeat purchase, positive word-of-mouth, resistance to brand switching, and willing to pay a price premium (Ahearne et al. 2005; Haumann et al. 2014; Lam et al. 2010; Torres et al. 2018). Also, from the consumer-company identification framework (Bhattacharya and Sen 2003), highly identified consumers will exhibit effort-intensive behaviors (e.g., brand loyalty, brand promotion, customer recruitment, and resilience to negative information) in order to enhance their favorite brand's long-term welfare. An implication from these theories is that once consumers identify with a particular brand, the connection plays a key role in increasing their behavioral engagement in the brand over time. Since we focus on behavioral loyalty and purchase frequency as behavioral consequences, we develop the following hypotheses:

H5a CBI has a positive impact on behavioral loyalty.

H5b CBI has a positive impact on purchase frequency. 


\section{The moderating effect of consumer happiness}

The joint investigation of CBI and consumer happiness allows us to further explain the CBI-loyalty relationship. To this end, we propose that consumer happiness moderates the impact of CBI on behavioral consequences. This prediction is supported by the broaden-and-build theory (Fredrickson 2001) which suggests that positive emotions, including happiness, are vehicles for individuals' personal growth and social well-being. According to this theory, psychologically well individuals are more likely to "broaden-and-build" the enduring resources necessary to achieve their goals. More specifically, receiving an increased supply of positive emotions, people are able to build physical (e.g., physical skills and health), intellectual (e.g., expert knowledge and problem solving skills), and social (e.g., social bonds and social support) resources and, as a result, become more healthy, knowledgeable, and socially connected with others. In consumer behavior, consistent positive feelings of happiness during brand consumption may help consumers build the enduring resources (physical, intellectual, and social resources) necessary to exhibit continual behavioral loyalty as a life-long endeavor (Fredrickson 2001). If brand consumption is not a pleasurable activity in life, the relationship between CBI and behavioral loyalty may not be significant. Conversely, the impact of CBI on behavioral loyalty will be stronger if consumers feel that brand consumption greatly contributes to their overall happiness (Guevarra and Howell 2015). Therefore, we expect that consumer happiness amplifies the extent to which highly identified brand consumers remain loyal to their favorite brands in a long-term perspective. These arguments lead us to the following hypotheses:

H6a Consumer happiness moderates the relationship between CBI and behavioral loyalty, such that the impact of $\mathrm{CBI}$ on behavioral loyalty will be stronger among those who have higher levels of consumer happiness.

H6b Consumer happiness moderates the relationship between $\mathrm{CBI}$ and purchase frequency, such that the impact of $\mathrm{CBI}$ on purchase frequency will be stronger among those who have higher levels of consumer happiness.

\section{Replication effects}

In addition to the hypothesized effects, the impact of brand prestige and brand distinctiveness on CBI will be positive and significant. Organizational identification theory allows for the proposition that individuals tend to (1) identify themselves with prestigious brands and (2) have a strong desire for brand identification by seeking positive differences (e.g., a sharper and more salient definition for brands) between themselves and reference groups (Ashforth and Mael 1989).
In order to replicate the relationships reported in previous research (Bhattacharya et al. 1995; Stokburger-Sauer et al. 2014), we expect that brand prestige and brand distinctiveness will have a positive impact on CBI.

\section{Methods}

\section{Research setting}

The research context was professional football in Japan; this context was suitable for several reasons. First, professional football is a hedonic and experiential product. Hedonic and experiential consumption promotes consumer happiness due to the increased levels of social connectedness (Gilovich et al. 2015) and positive affect (Ryan and Deci 2001). The current setting is an ideal exemplar to examine how CBI and consumer happiness jointly influence consumer loyalty. Second, many football fans share their consumption experiences in their brand communities and tend to identify with their favorite team brands (Mazodier et al. 2018; Oliver 1999). Key variables such as social interaction ties, shared vision, and CBI are readily identified and assessed in this context.

In order to achieve our objectives, we used consumer survey data collected over six months. Data were collected from local residents who lived in the hometown area of a Division 1 team of the Japan Professional Football League (J. League). The key strengths in choosing this setting include (1) measuring football fans' social capital, CBI, and happiness and (2) collecting data over the course of a season. The present study was conducted throughout the 2017 season.

\section{Data collection}

We gathered data from panel surveys conducted by Macromill, Inc., one of the major online research service firms in Japan. The research company randomly sent an invitation email to panel registrants who lived in six cities (Chofu, Mitaka, Fuchu, Koganei, Kodaira, and Nishi Tokyo) in Tokyo because these cities are the official franchise cities set by a professional football team based in Tokyo. One thousand and thirty respondents participated in the survey and answered questions on $\mathrm{CBI}$ and its predictor variables. Second, the research company asked the same subjects to rate two behavioral outcomes at the end of the season; data were collected from 618 subjects. Third, we eliminated 244 respondents because their length of time as a fan was zero. Overall, data were retained from 374 local residents, yielding a usable response rate of $36.3 \%$.

In terms of the sample characteristics, $68.7 \%$ of the respondents were male. The average age of the subjects was 51.59 years old (standard deviation $=11.62$ ). Age was also categorized into five groups. More than one-third of 
the subjects were in the 50 to 59 age range (37.2\%), $28.9 \%$ were between 40 and 49 years old, $21.4 \%$ were 60 years old and above, $8.8 \%$ were between 30 and 39 years old, and $3.7 \%$ were 20 and 29 years old.

Non-response bias was addressed by comparing the respondents to the non-respondents and to the population (Miller and Smith 1983). First, we compared the mean scores of the Time 1 variables between our sample $(n=374)$ and those who did not participate in the second survey, but followed the club and responded to the first survey $(n=224)$. No significant difference was found on CBI, brand prestige, and brand distinctiveness, while social interaction ties, shared vision, and consumer happiness were slightly higher for the respondents than for the non-respondents $(p<0.05)$. Second, we compared sample characteristics with population characteristics. According to the J. League Annual Survey Report (League 2018) which was based on the data collected from 17,136 game attendees of all teams, the gender distribution ( male $=61.9 \%$, female $=38.1 \%$ ) of the national survey was similar to that of our sample (male $=68.7 \%$, female $=31.3 \%$ ). However, the average age of our sample $(\mathrm{M}=51.59)$ was higher than that of the national population $(\mathrm{M}=41.70)$. We gathered data from local residents that included many elderly people. Collectively, we consider our sample as nearly representative of the overall population for this study.

\section{Measures}

We adopted items used to measure the constructs from previous research. Consistent with previous studies (e.g., Bhattacharya et al. 1995; Haumann et al. 2014), we used Mael and Ashforth's (1992) scale to measure CBI. A three-item scale for measuring brand prestige was adopted from Hur, Kim, and Woo's (2014) reputation scale. Brand distinctiveness was measured with a three-item scale adopted from the work of Jones and Volpe (2011) and Carlson et al. (2009). Social interaction ties were measured with a three-item scale adopted from the scale used by Chiu et al. (2006). Shared vision was also measured with a three-item scale adopted from Chiu et al.'s (2006) scale.

In order to measure behavioral loyalty, a five-item scale was adopted from two validated scales in the literature. Based on Oliver's (1999) conceptualization of action loyalty, we selected five items from Zeithaml et al.'s (1996) customer loyalty scale and Garnefeld and colleagues' (2013) behavioral loyalty scale. Also, behavioral loyalty can also be measured by summing the purchase frequency of consumers over a particular period (Seiders et al. 2005). In this study, we measured purchase frequency by asking the number of games attended by each respondent in the last nine months (Yoshida et al. 2015).
To test the proposed moderating effect, we identified consumer happiness which refers to a positive psychological state that results from a pleasurable consumption experience and contributes to the quality of life (van Boven and Gilovich 2003). We measured consumer happiness with a two-item scale adopted from van Boven and Gilovich (2003). In this study, the survey items for the seven latent constructs were measured on a 7-point Likert-type scale (see Table 1).

\section{Back translation}

A back-translation procedure (De Wulf et al. 2001; Yoshida et al. 2015) was used to translate the English-based survey items into Japanese. First, one of the authors who is fluent in both Japanese and English translated the English survey items into Japanese. Second, the translated items were then back-translated into English by another bilingual Japanese. To check the accuracy of the translation, a US-born American researcher assessed differences in meaning between the original and back translated instruments. From these procedures, we concluded that the two forms equally reflected each construct domain.

\section{Results}

\section{Assessment of the measurement model}

To examine the psychometric properties of our measures, we conducted a confirmatory factor analysis (CFA) using Mplus Version 7.31 (see Table 1). The comparative fit index (CFI) and Tucker Lewis index (TLI) were greater than the cutoff point of 0.90 (Hu and Bentler 1999). The values of the root mean square error of approximation (RMSEA) and standardized root mean square residual (SRMR) were smaller than the recommended value of 0.08 ( $\mathrm{Hu}$ and Bentler 1999). While the ratio of chi-square to degrees of freedom $\left(\chi^{2} / \mathrm{df}\right)$ was higher than $\mathrm{Hu}$ and Bentler's (1999) recommendation of 3.0, overall the fit is acceptable when looking at all the evidence.

Factor loadings $(\lambda)$, composite reliability $(\mathrm{CR})$ and average variance extracted (AVE) values are also shown in Table 1. Factor loadings ranged from 0.77 to 0.97 . The CR values for the seven latent constructs exceeded the recommended level of 0.60 (Bagozzi and Yi 1988). Further, we assessed convergent and discriminant validity by estimating AVE values. The AVE values for the seven latent constructs ranged from 0.69 to 0.87 , providing evidence of convergent validity (Fornell and Larcker 1981). Moreover, the AVE value of each construct was greater than the square of its correlation with any other constructs (Table 2). Thus, there was evidence of discriminant validity. 
Table 1 Scale items and confirmatory factor analysis

\begin{tabular}{|c|c|c|c|c|}
\hline Construct & Item & $\lambda$ & $\mathrm{CR}$ & AVE \\
\hline Social interaction ties (Chiu et al. 2006) & & & .92 & .75 \\
\hline 1 & I maintain a very close relationship with some fans of (brand name) & .86 & & \\
\hline 2 & I spend much time interacting with some fans of (brand name) & .90 & & \\
\hline 3 & I personally know some fans of (brand name) & .83 & & \\
\hline 4 & I frequently communicate with some fans of (brand name) & .88 & & \\
\hline Shared vision (Chiu et al. 2006) & & & .93 & .81 \\
\hline 1 & I share the same vision with other fans of (brand name) & .86 & & \\
\hline 2 & I share the same goal with other fans of (brand name) & .92 & & \\
\hline 3 & I share the same values with other fans of (brand name) & .92 & & \\
\hline Brand prestige (Hur et al. 2014) & & & .87 & .69 \\
\hline 1 & I have a good feeling about (brand name) & .85 & & \\
\hline 2 & Overall, (brand name) has a good reputation & .77 & & \\
\hline 3 & I admire and respect (brand name) & .87 & & \\
\hline Brand distinctiveness (Carlson et al. 2009; Jones and Volpe 2011 & & & .93 & .82 \\
\hline 1 & I feel (brand name) is unlike any other team & .84 & & \\
\hline 2 & (Brand name) has unique characteristics compared to other teams & .96 & & \\
\hline 3 & I believe (brand name) is very unique as compared to other teams & .91 & & \\
\hline CBI (Mael and Ashforth 1992) & & & .93 & .69 \\
\hline 1 & I am very interested in what others think about (brand name) & .79 & & \\
\hline 2 & When someone criticizes (brand name), it feels like a personal insult & .79 & & \\
\hline 3 & When I talk about (brand name), I usually say "we" rather than "they." & .82 & & \\
\hline 4 & (Brand name)'s successes are my successes & .88 & & \\
\hline 5 & When someone praises (brand name), it feels like a personal compliment & .92 & & \\
\hline 6 & If a story in the media criticized (brand name), I would feel embarrassed & .77 & & \\
\hline Consumer happiness (Van Boven and Gilovich 2003) & & & .93 & .87 \\
\hline 1 & Watching (brand name)'s games greatly contributes to my happiness in life & .97 & & \\
\hline 2 & Thinking about watching (brand name)'s games makes me very happy & .89 & & \\
\hline Behavioral loyalty (Garnefeld et al. 2013; Zeithaml et al. 1996) & & & .95 & .79 \\
\hline 1 & I often say positive things to a friend about (brand name) & .87 & & \\
\hline 2 & I encourage friends to follow (brand name) & .85 & & \\
\hline 3 & $\begin{array}{l}\text { In the next few years, I buy more apparel products which display the logo of (brand } \\
\text { name) }\end{array}$ & .88 & & \\
\hline 4 & If (brand name) raised ticket prices, I would continue to attend (brand name)'s games & .94 & & \\
\hline 5 & $\begin{array}{l}\text { If (brand name) has an unsuccessful season, I would continue to watch (brand name)'s } \\
\text { games at the stadium }\end{array}$ & .89 & & \\
\hline
\end{tabular}

$\chi^{2}(d f)=790.23(278), \chi^{2} / d f=2.84, \mathrm{CFI}=.95, \mathrm{TLI}=.94, \mathrm{RMSEA}=.070, \mathrm{SRMR}=.035$

Table 2 Descriptive statistics and correlations (latent constructs)

\begin{tabular}{|c|c|c|c|c|c|c|c|c|c|c|}
\hline \multicolumn{2}{|c|}{ Construct } & \multirow[t]{2}{*}{ M } & \multirow[t]{2}{*}{ SD } & \multicolumn{7}{|c|}{$\Phi$ matrix $(n=374)$} \\
\hline & & & & 1 & 2 & 3 & 4 & 5 & 6 & 7 \\
\hline 1 & Social interaction ties (Time 1) & 2.63 & 1.62 & .75 & .54 & .22 & .34 & .51 & .39 & .47 \\
\hline 2 & Shared vision (Time 1) & 3.27 & 1.59 & .74 & .81 & .44 & .48 & .68 & .55 & .40 \\
\hline 3 & Brand prestige (Time 1) & 4.87 & 1.19 & .47 & .67 & .69 & .53 & .37 & .39 & .26 \\
\hline 4 & Brand distinctiveness (Time 1) & 3.81 & 1.38 & .59 & .70 & .73 & .82 & .44 & .35 & .32 \\
\hline 5 & CBI (Time 1) & 3.08 & 1.44 & .71 & .82 & .61 & .67 & .69 & .61 & .46 \\
\hline 6 & Consumer happiness (Time 1) & 3.34 & 1.63 & .63 & .74 & .63 & .59 & .78 & .87 & .46 \\
\hline 7 & Behavioral loyalty (Time 2) & 2.49 & 1.56 & .68 & .63 & .51 & .56 & .68 & .68 & .79 \\
\hline
\end{tabular}

Correlations are taken from $\phi$ matrix using Mplus 7.31 and are shown in the lower triangle of the $\phi$ matrix. Squared correlations are reported in the upper triangle of the $\phi$ matrix. The average variance extracted values for the seven latent constructs are depicted in boldface italic on the diagonal. The mean scores and standard deviations for the proposed constructs were calculated using IBM SPSS Statistics 25.0

All correlations are statistically significant at the .01 level $(p<.01)$ 


\section{Model comparisons}

Using Mplus Version 7.31, structural equation modeling (SEM) was next employed as a test of the predictive power of some of the Time 1 variables (social interaction ties, shared vision, and CBI) on the Time 2 variables (brand loyalty and purchase frequency). However, our hypothesized model does not allow us to examine possible direct effects of brand prestige and brand distinctiveness on the Time 2 outcomes. To fully test the direct impact of the predictor variables, we compared the hypothesized model (Model 1) with a competing nested SEM model (Model 2) which included the direct paths from brand prestige and brand distinctiveness to brand loyalty and purchase frequency. We performed a chi-square difference test and found that (1) Model 1 was a better fit to the data than Model 2 and (2) there was no significant improvement between Model 1 and Model 2: $\Delta \chi^{2}$ $(\Delta d f)=8.85(4)$, n.s (see Table 3). Moreover, none of the added paths from brand prestige and brand distinctiveness to the Time 2 variables were significant.
Furthermore, while we hypothesized social interaction ties influence CBI, this relationship can be reversed because CBI results in social networking behavior (Bhattacharya and Sen 2003). Thus, we conducted an additional chi-square difference test between the hypothesized model (social interaction ties $\rightarrow \mathrm{CBI}$ ) and an alternative model (CBI $\rightarrow$ social interaction ties). The results indicated that the model fit of the hypothesized model was significantly better than the alternative model: $\Delta \chi^{2}(\Delta d f)=41.92(3), p<0.01$. Collectively, we concluded that our hypothesized model is adequate for assessing the relationships between the proposed constructs.

\section{Assessment of the structural model}

We examined the hypothesized relationships using SEM (see Model 1 in Table 3). The fit indices for the hypothesized model were $\chi^{2} / d f=3.07, \mathrm{CFI}=0.94$, TLI $=0.93$, RMSEA $=0.074$, and SRMR $=0.039$, indicating that the fit measures were acceptable. With respect to hypothesis

Table 3 Results of model comparison

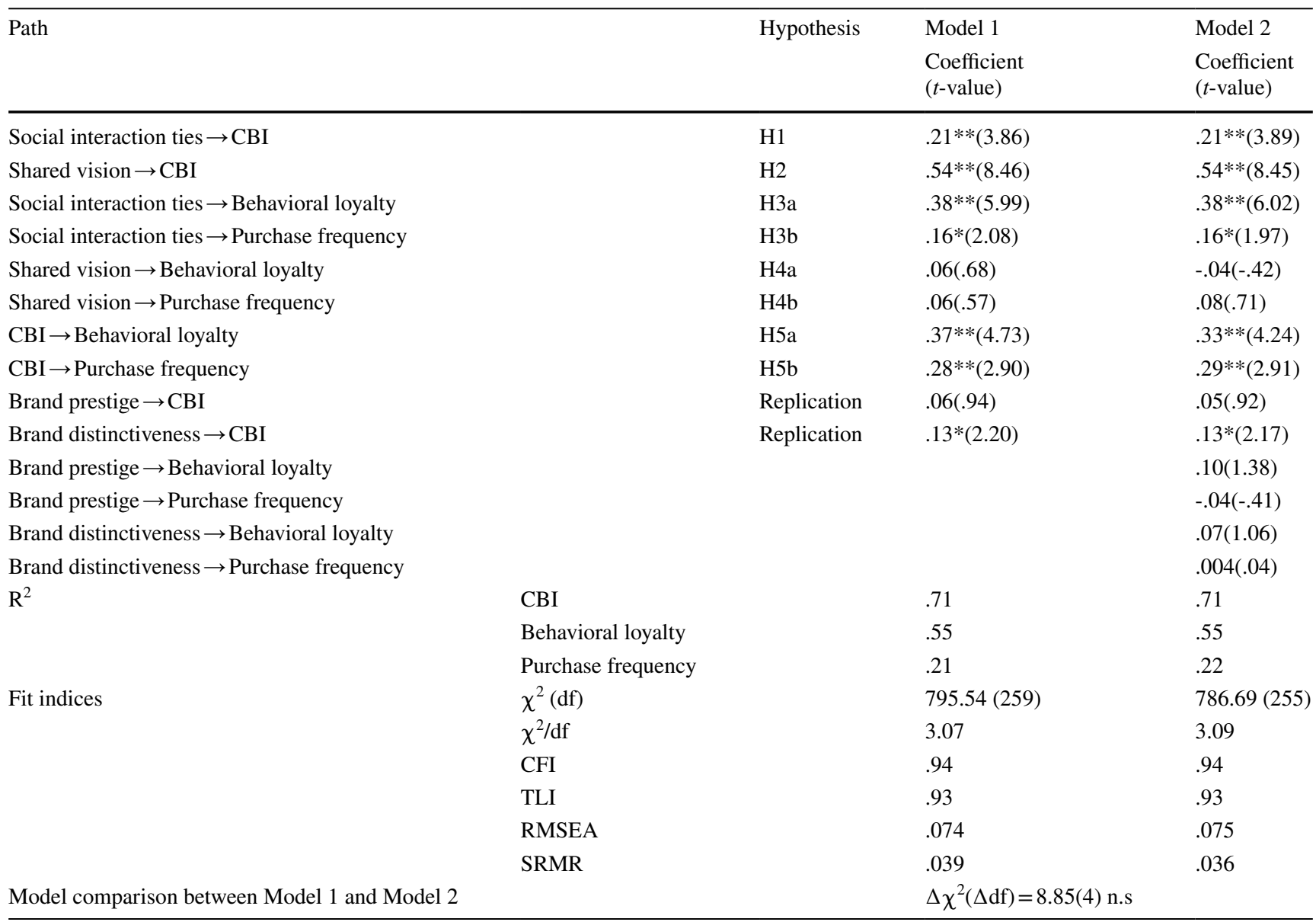

The critical values for a $\chi^{2}$ with $d f=4$ are 9.49 at the .05 level and 13.28 at the .01 level

$* p<.05, * * p<.01$ 
testing, social interaction ties $(\gamma=0.21, \mathrm{p}<0.01)$, shared vision $(\gamma=0.54, \mathrm{p}<0.01)$, and brand distinctiveness $(\gamma=0.13, p<0.05)$ had positive effects on CBI in support of $\mathrm{H} 1$, and $\mathrm{H} 2$, whereas the replication effect of brand prestige on CBI was rejected. Also, social interaction ties were found to positively influence both behavioral loyalty $(\beta=0.38$, $p<0.01)$ and purchase frequency $(\beta=0.16, p<0.05)$. Moreover, the effects of CBI on behavioral loyalty $(\beta=0.37$, $p<0.01)$ and purchase frequency $(\beta=0.28, p<0.01)$ were positive and significant. These results provided support for H3a, H3b, H5a, and H5b, while H4a and H4b were not supported. The extent to which the exogenous variables provide an explanation of variations in the endogenous variables was assessed by $R^{2}$ values (see Table 3 ). The $R^{2}$ values for CBI, behavioral loyalty, and purchase frequency were $0.71,0.55$, and 0.21 , respectively.

Our hypothesized model not only demonstrates the direct impact of CBI and its predictor variables on the two outcome variables, but also suggests the indirect impact of the predictor variables on the two outcomes through CBI. To test the indirect effects of the predictor variables on the two behavioral outcomes through CBI, we used the bootstrapping method recommended by Preacher and Hayes (2008). The mediation analysis was performed using Mplus Version 7.31 (see Table 4). A bootstrap estimation with 5000 resamples revealed the $95 \%$ confidence intervals (CIs) for the indirect effects of social interaction ties and shared vision on behavioral loyalty through CBI did not include zero. Similarly, the results showed the $95 \%$ CIs were greater than zero for the indirect effects of social interaction ties and shared vision on purchase frequency. These findings provide evidence that CBI mediated the effects of social interaction ties and shared vision on behavioral loyalty and purchase frequency.

\section{Moderating effects}

To test the moderating impact of consumer happiness on the relationship between $\mathrm{CBI}$ and behavioral consequences
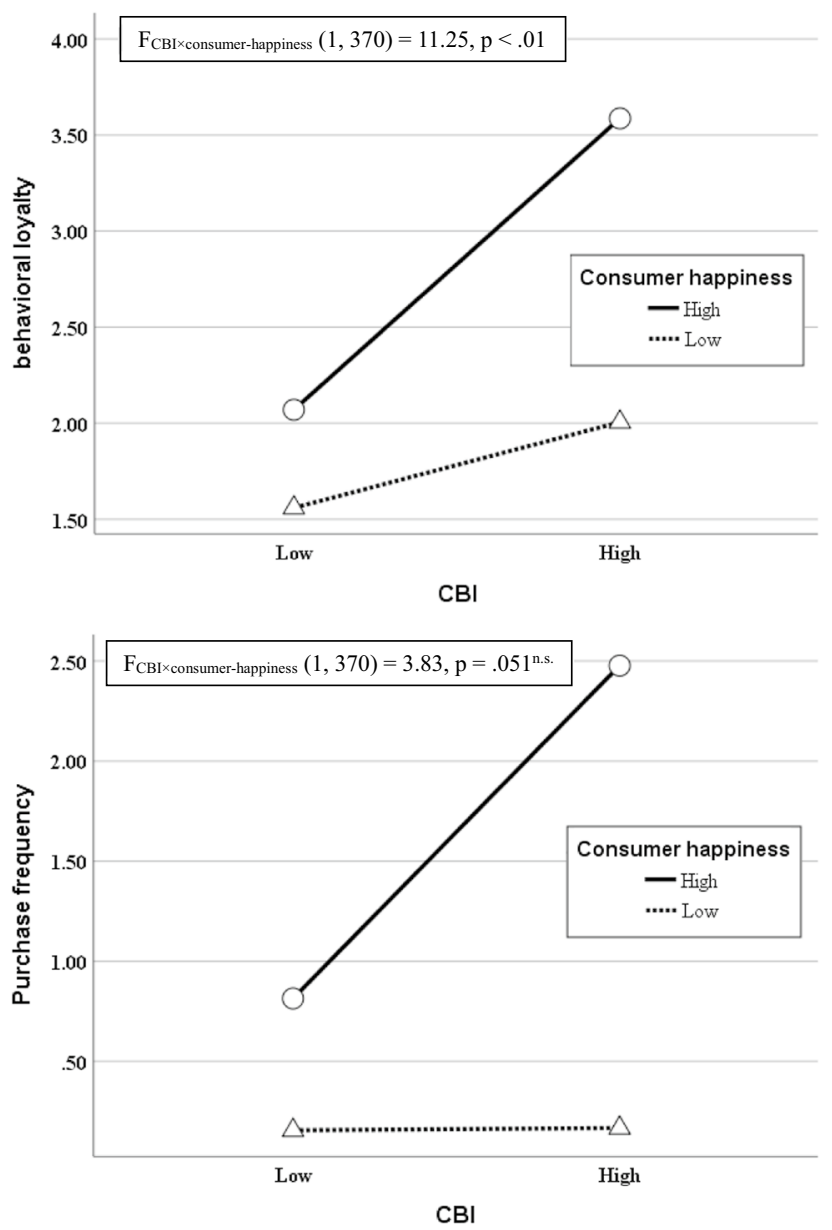

Fig. 2 Moderating effects of consumer happiness on the relationships between CBI and behavioral outcomes
Table 4 Indirect effects for the hypothesized structural model

\begin{tabular}{lllllll}
\hline Indirect effect & \multicolumn{2}{l}{ Bootstrap estimate } & & \multicolumn{2}{l}{$95 \%$ CI } \\
\cline { 2 - 4 } \cline { 5 - 6 } & $\begin{array}{l}\text { Standard- } \\
\text { ized effect }\end{array}$ & $\begin{array}{l}\text { Unstandard- } \\
\text { ized effect }\end{array}$ & SE & Lower & Upper \\
\hline Social interaction ties $\rightarrow \mathrm{CBI} \rightarrow$ Behavioral loyalty & $.08^{*}$ & $.07^{*}$ & .03 & .03 & .15 \\
Social interaction ties $\rightarrow \mathrm{CBI} \rightarrow$ Purchase frequency & $.06^{*}$ & $.13^{*}$ & .03 & .03 & .31 \\
Shared vision $\rightarrow \mathrm{CBI} \rightarrow$ Behavioral loyalty & $.20^{*}$ & $.21^{*}$ & .07 & .09 & .37 \\
Shared vision $\rightarrow \mathrm{CBI} \rightarrow$ Purchase frequency & $.15^{*}$ & $.37^{*}$ & .07 & .09 & .78 \\
Brand prestige $\rightarrow \mathrm{CBI} \rightarrow$ Behavioral loyalty & .02 & .03 & .03 & -.04 & .12 \\
Brand prestige $\rightarrow \mathrm{CBI} \rightarrow$ Purchase frequency & .02 & .05 & .02 & -.07 & .22 \\
Brand distinctiveness $\rightarrow \mathrm{CBI} \rightarrow$ Behavioral loyalty & .05 & .05 & .03 & -.02 & .15 \\
Brand distinctiveness $\rightarrow \mathrm{CBI} \rightarrow$ Purchase frequency & .04 & .10 & .03 & -.02 & .32 \\
\hline
\end{tabular}

$\mathrm{CBI}=$ consumer-brand identification, $\mathrm{CI}=$ confidence interval $* p<.05$ 
(predict behavioral loyalty and purchase frequency), we performed a $2(\mathrm{CBI}) \times 2$ (consumer happiness) analysis of variance (ANOVA, see Fig. 2). The subjects were assigned into the low and high levels of CBI and into the low and high levels of consumer happiness using a median split ( median $_{\mathrm{CBI}}=3.0$; median $_{\text {consumer-happiness }}=3.0$ ). Using behavioral loyalty as the dependent variable, we found significant main effects of CBI $(F[1,370]=37.83, p<0.01)$ and consumer happiness $(F[1,370]=42.94, p<0.01)$. Of greatest importance, a two-way ANOVA revealed a significant $\mathrm{CBI} \times$ consumer-happiness interaction effect $(F[1$, $370]=11.25, p<0.01)$. Within the high consumer happiness condition, the respondents with high CBI reported higher behavioral loyalty $(M=3.59)$ than those with low CBI $(M=2.07)$. However, within the low consumer happiness condition, no difference was found between highly identified $(M=2.07)$ and lowly identified $(M=1.56)$ brand consumers. Thus, we found support for H6a.

We also tested a two-way ANOVA using CBI and consumer happiness as predictor variables and purchase frequency as the dependent variable (see Fig. 2). While the main effects of CBI $(F[1,370]=3.93, p<0.05)$ and consumer happiness $(F[1,370]=12.38, p<0.01)$ on purchase frequency were positive and significant, the two-way interaction of CBI and consumer happiness did not reach statistical significance $(F[1,370]=3.83, p=0.051)$. Thus, H6b was rejected although the results showed a similar tendency to the findings of behavioral loyalty. Collectively, these results indicate that the impact of CBI on behavioral loyalty is contingent on consumer happiness.

\section{Discussion}

\section{Theoretical implications}

Whetten (1989) contends that providing new insights into previous theories can be considered as theoretical contributions. Heeding this guidance, in the following section, we discuss how this study suggests modifications in existing theories and why such modifications would work with alternative explanations.

First, we extend the brand identification literature by challenging the previous assumption that brand characteristics (e.g., prestige and distinctiveness) are the primary antecedents of CBI (Bhattacharya and Sen 2003; Stokburger-Sauer et al. 2014). We found that CBI was more strongly affected by the two social capital factors than by brand prestige and brand distinctiveness (see Table 3). Based on these results we suggest that $\mathrm{CBI}$ is more closely related to the cognitive (shared vision) and structural (social interaction ties) dimensions of social capital than brand prestige and brand distinctiveness. This is consistent with previous studies that suggest (1) building social bonds among consumers in brand communities fosters CBI (Bagozzi and Dholakia 2006) and (2) social benefits, such as the social interactions among fellow brand users, have a stronger effect on CBI than brand prestige and brand distinctiveness (Stokburger-Sauer et al. 2014). Although brand characteristics (e.g., prestige and distinctiveness) have helped to shape our understanding of an important route to CBI, the structural and cognitive dimensions of social capital that consumers possess in pursuit of their consumption goals in brand communities represent a new perspective on why people identify with brands.

Second, this work is unique because it investigated the mediating role of CBI in a predictive study. Since little effort has been made to examine the impact of CBI and its antecedents on behavioral consequences over time (Haumann et al. 2014; Huang et al. 2017), the current study contributes to the brand management literature with a more precise explanation of the hypothesized relationships. The results (Table 4) support the notion that the structural (social interaction ties) and cognitive (shared vision) dimensions of social capital first influence CBI which in turn predicts behavioral loyalty and purchase frequency. These findings are consistent with the theoretical perspective of Tsai and Ghoshal (1998) who suggest that social interaction ties and shared vision induce more loyalty to an organization through building relational social capital because close social interactions and common goals allow individuals to share important information, promote the harmony of social relationships, and eventually result in ongoing organizational support. Our study provided initial support for such sequential relationships in brand management research.

Our results also indicate that consumers' behavioral consequences are more strongly associated with their social networking behavior (structural social capital) and CBI (relational social capital) than with shared vision (cognitive social capital). The results provide evidence for Oliver's (1999) village concept, suggesting if a brand not only reflects a consumer's personal identity, but also involves rich social interactions with other consumers, fully bonded loyalty emerges as a blend of self-concept with social bonds in the consumption village. Therefore, fostering CBI is not enough wherein providing opportunities to socialize with other consumers can also enhance behavioral brand loyalty.

In addition to the aforementioned points, our research contributes to the brand management literature by explaining how the impact of CBI on future behavioral loyalty is contingent on consumer happiness. Our moderator analysis indicated that CBI significantly influenced behavioral loyalty among those with high consumer happiness. Also, the moderating effect of consumer happiness on purchase frequency approached significance $(p=0.051)$, leading us to speculate happy consumers are more likely to have higher purchase frequency over time. These findings are consistent 
with the view that individuals with higher levels of happiness are more interested in and committed to the activity they perform (Frey 2017). A growing literature has emerged to explain how happiness is related to positive behavior (e.g., Fredrickson 2001; Luthans et al. 2008). For happy consumers, their brand consumption becomes more meaningful, aspirational, and sustainable (Huang and Rust 2011; Sheth et al. 2011) because such consumers can build and use their resources (e.g., physical, intellectual, and social resources) to achieve their desirable consumption goals (Fredrickson 2001). Thus, it seems reasonable to believe that consumer happiness improves the impact of CBI on consumers' longterm pursuit of behavioral loyalty. Collectively, this study is a compelling extension of previous CBI research in which the role of consumer happiness was not explicitly discussed.

Although we did not expect that the direct impact of brand prestige on CBI would be insignificant, this finding is also consistent with previous research. Jones and Volpe (2011) did not find a significant effect of organizational prestige on organizational identification because when competitors have equivalent or better prestige, organizational prestige may not lead to organizational identification. While ranked in the top five at the beginning (March) of the 2017 season, the focal football team dropped to tenth in the standings (out of eighteen teams) during the first data collection (July) and finished thirteenth at the end of the season (December). Thus, a possible explanation is that the team's poor performance damaged the prestigious reputation of the team and prevented the consumers from evaluating team prestige at a high level. While brand prestige is context-specific, consumers' brand identification is stable and enduring as many sports fans' identification with their teams is grounded in childhood (James 2001).

\section{Managerial implications}

Our conceptual framework and the study results signify that managers can enhance CBI and behavioral consequences through consumer-to-consumer social capital (i.e., social interaction ties and shared vision). For example, practitioners can expect that providing social interaction opportunities in both face-to-face and online social networks and communicating information about their mission, vision, and values will lead to higher levels of CBI and behavioral loyalty over time. In particular, service managers should recognize that consumer-to-consumer social capital helps ensure higher levels of CBI as well as consumer loyalty. From a practical standpoint, one implication from this study is that service managers need to make an effort not only to improve their brand characteristics (e.g., prestige and distinctiveness), but to also include consumer-to-consumer social interactions in their long-term loyalty strategies. Evidence of this can be found in the realm of sports where the inclusion of plazas at sports stadiums as social spaces for fans to gather in and around the stadium is a recent design trend to foster fan-tofan connectivity as well as provide revenue opportunities year round (Muret 2016).

The results of this study also indicate that consumer happiness enhances the impact of CBI on future behavioral loyalty. Therefore, practitioners should place great emphasis on the importance of consumer happiness in their marketing actions. For instance, the utilization of marketing messages with an emphasis on well-being may foster a positive brand image among consumers. An example of such branding can be seen in the fact that many companies attempt to associate their marketing campaigns with Goal 3 (good health and well-being) of the United Nations' sustainable development goals (SDGs). Also, another practical application of this study can be carried out as an advertising campaign that shows attractive photographs and graphics featuring happy brand consumers. It would be effective to send these consumers' visual messages via websites, social media, and mobile platforms as well as traditional media including television, newspapers, and magazines. Furthermore, in order to achieve long-term brand loyalty, brand consumption must be meaningful and sustainable for consumers in the face of societal grand challenges such as climate change, aging society, international migration, racial discrimination, and the COVID-19 pandemic. Marketing communications must be authentic and credible to make a meaningful contribution to the lives of consumers even during adverse times.

\section{Limitations and directions for future research}

This study has several limitations that can be addressed in future research. First, this study was conducted in a professional football context. One limitation of the present study is the lack of generalizability of the findings to other settings. The consumption of professional football is hedonic (Funk and James 2001) and experiential (Yoshida 2017). With an increased emphasis on hedonic consumption (Hirschman and Holbrook 1982) and experiential consumption (Pine and Gilmore 1998; Schmitt et al. 2015) in developed countries, hedonic and experiential products are important in the pursuit of happiness among modern consumers (van Boven and Gilovich 2003; Zhong and Mitchell 2010). In future studies, researchers should carefully examine the interaction effect of CBI and consumer happiness on brand loyalty in various contexts of hedonic and experiential products.

Second, the proposed framework was tested in the context of Japanese professional football. Considering that Japan has a collectivist culture (Hofstede 2001), it should be acknowledged that this collectivism might strengthen the relationships between the proposed constructs. In particular, 
this cultural characteristic may have inflated the predictive power of social interaction ties and shared vision for CBI and behavioral consequences. It will be interesting to replicate this study in a different cultural context.

Third, another limitation is the omission of potentially important variables. While we integrated organizational identification theory and organization social capital theory in our research model, additional variables might influence behavioral loyalty and purchase frequency. For example, previous research has shown that consumer satisfaction, commitment, and engagement positively affect the behavioral consequences of consumer-brand relationships (Pansari and Kumar 2017). It will be interesting to see how future researchers examine the simultaneous effects of these attitudinal and behavioral constructs on consumers' future consumption behavior.

\section{Conclusion}

This study represents an initial effort to provide evidence of the predictive validity of $\mathrm{CBI}$ and its antecedents in relation to consumer happiness and future behavioral consequences. Particularly, incorporating social capital and consumer happiness perspectives into CBI research extends scholars' and managers' ability to better understand and explain the predictive power of $\mathrm{CBI}$ and its antecedents over time.

Acknowledgements This study was financially supported by the Japanese Society for the Promotion of Science (No. 17K13163).

\section{Declaration}

Conflict of interest On behalf of all authors, the corresponding author states that there is no conflict of interest.

\section{References}

Ahearne, M., C.B. Bhattacharya, and T. Gruen. 2005. Antecedents and consequences of customer-company identification: Expanding the role of relationship marketing. Journal of Applied Psychology 90 (3): 574-585.

Anderson, L., A.L. Ostrom, C. Corus, R.P. Fisk, A.S. Gallan, M. Giraldo, M. Mende, M. Mulder, S. Rayburn, M. Rosenbaum, K. Shirahada, and J.D. Williams. 2013. Transformative service research: An agenda for the future. Journal of Business Research 66 (8): 1203-1210.

Ashforth, B.E., and F.A. Mael. 1989. Social identity theory and the organization. Academy of Management Review 14 (1): 20-39.

Augusto, M., and P. Torres. 2018. Effects of brand attitude and eWOM on consumers' willingness to pay in the banking industry: Mediating role of consumer-brand identification and brand equity. Journal of Retailing and Consumer Services 42: 1-10.

Bagozzi, R.P., and U.M. Dholakia. 2006. Antecedents and purchase consequences of customer participation in small group brand communities. International Journal of Research in Marketing 23: 45-61.

Bagozzi, R.P., and Y. Yi. 1988. On the evaluation of structural equation models. Journal of the Academy of Marketing Science 16 (1): 74-94.

Balmer, J.M.T. 2012. Strategic corporate brand alignment: Perspectives from identity based views of corporate brands. European Journal of Marketing 46 (7/8): 1064-1092.

Bergami, M., and R.P. Bagozzi. 2000. Self-categorization, affective commitment and group self-esteem as distinct aspects of social identity in the organization. British Journal of Social Psychology 39: 555-577.

Bhattacharjee, A., and C. Mogilner. 2014. Happiness from ordinary and extraordinary experiences. Journal of Consumer Research 41 (1): 1-17.

Bhattacharya, C.B., H. Rao, and M.A. Glynn. 1995. Understanding the bond of identification: An investigation of its correlates among art museum members. Journal of Marketing 59 (4): 46-57.

Bhattacharya, C.B., and S. Sen. 2003. Consumer-company identification: A framework for understanding consumers' relationships with companies. Journal of Marketing 67 (2): 76-88.

Carlson, B.D., D.T. Donovan, and K.J. Cumiskey. 2009. Consumerbrand relationships in sport: Brand personality and identification. International Journal of Retail \& Distribution Management 37 (4): 370-384.

Chiu, C.M., M.H. Hsu, and E.T.G. Wang. 2006. Understanding knowledge sharing in virtual communities: An integration of social capital and social cognitive theories. Decision Support Systems 42 (3): $1872-1888$

Csikszentmihalyi, M. 2000. The costs and benefits of consuming. Journal of Consumer Research 27 (2): 267-272.

De Wulf, K., G. Odekerken-Schröder, and D. Iacobucci. 2001. Investments in consumer relationships: A cross-country and crossindustry exploration. Journal of Marketing 65 (4): 33-50.

Devezer, B., D.E. Sprott, E.R. Spangenberg, and S. Czellar. 2014. Consumer well-being: Effects of subgoal failures and goal importance. Journal of Marketing 78 (2): 118-134.

Fornell, C., and D.F. Larcker. 1981. Evaluating structural equation models with unobservable variables and measurement error. Journal of Marketing Research 18 (1): 39-50.

Fredrickson, B.L. 2001. The role of positive emotions in positive psychology: The broaden-and-build theory of positive emotions. American Psychologist 56 (3): 218-226.

Frey, B.S. 2017. Research on well-being: Determinants, effects, and its relevance for management. Die Unternehmung 71 (4): 358-367.

Funk, D.C., and J.D. James. 2001. The Psychological continuum model: A conceptual framework for understanding an individual's psychological connection to sport. Sport Management Review 4 (2): 119-150.

Garnefeld, I., A. Eggert, S.V. Helm, and S.S. Tax. 2013. Growing existing customers' revenue streams through customer referral programs. Journal of Marketing 77 (4): 17-32.

Gilovich, T., A. Kumar, and L. Jampol. 2015. A wonderful life: Experiential consumption and the pursuit of happiness. Journal of Consumer Psychology 25 (1): 152-165.

Guevarra, D.A., and R.T. Howell. 2015. To have in order to do: Exploring the effects of consuming experiential products on well-being. Journal of Consumer Psychology 25 (1): 28-41.

Haumann, T., B. Quaiser, J. Wieseke, and M. Rese. 2014. Footprints in the sands of time: A comparative analysis of the effectiveness of customer satisfaction and customer-company identification over time. Journal of Marketing 78 (6): 78-102.

Healy, J.C., and P. McDonagh. 2013. Consumer roles in brand culture and value co-creation in virtual communities. Journal of Business Research 66: 1528-1540. 
Hirschman, E.C., and M.B. Holbrook. 1982. Hedonic consumption: Emerging concepts, methods and propositions. Journal of Marketing 46 (3): 92-102.

Hofstede, G. 2001. Culture's consequences: Comparing values, behaviors, institutions, and organizations across nations, 2nd ed. Thousand Oaks, CA: Sage Publications.

Hu, L.T., and P.M. Bentler. 1999. Cutoff criteria for fit indexes in covariance structure analysis: conventional criteria versus new alternatives. Structural Equation Modeling 6 (1): 1-55.

Huang, M.H., Z.H. Cheng, and I.C. Chen. 2017. The importance of CSR in forming customer-company identification and long-term loyalty. Journal of Services Marketing 31 (1): 63-72.

Huang, M.H., and R.T. Rust. 2011. Sustainability and consumption. Journal of the Academy of Marketing Science 39: 40-54.

Hur, W.M., H. Kim, and J. Woo. 2014. How CSR leads to corporate brand equity: Mediating mechanisms of corporate brand credibility and reputation. Journal of Business Ethics 125 (1): 75-86.

James, J.D. 2001. The role of cognitive development and socialization in the initial development of team loyalty. Leisure Sciences 23 (4): 233-261.

Jones, C., and E.H. Volpe. 2011. Organizational identification: Extending our understanding of social identities through social networks. Journal of Organizational Behavior 32: 413-434.

Keller, K.L. 2008. Strategic brand management: Building, measuring and managing brand equity (2nd ed.), Upper Saddle River, NJ: Pearson/Prentice Hall.

Lam, S.K., M. Ahearne, Y. Hu, and N. Schillewaert. 2010. Resistance to brand switching when a radically new brand is introduced: A social identity theory perspective. Journal of Marketing 74 (6): 128-146.

Lam, S.K., M. Ahearne, R. Mullins, B. Hayati, and N. Schillewaert. 2013. Exploring the dynamics of antecedents to consumer-brand identification with a new brand. Journal of the Academy of Marketing Science 41: 234-252.

League, J. 2018. J. League fan survey 2017 summary report. Tokyo, Japan: Japan Professional Football League.

Lin, C.W., K.Y. Wang, S.H. Chang, and J.A. Lin. 2019. Investigating the development of brand loyalty in brand communities from a positive psychology perspective. Journal of Business Research 99: 446-455.

Luthans, F., S.M. Norman, B.J. Avolio, and J.B. Avey. 2008. The mediating role of psychological capital in the supportive organizational climate-employee performance relationship. Journal of Organizational Behavior 29: 219-238.

Mael, F., and B.E. Ashforth. 1992. Alumni and their alma mater: A partial test of the reformulated model of organizational identification. Journal of Organizational Behavior 13: 103-123.

Mathwick, C., C. Wiertz, and K. de Ruyter. 2007. Social capital production in a virtual P3 community. Journal of Consumer Research 34: 832-849.

Mazodier, M., C. Henderson, and J. Beck. 2018. The long reach of sponsorship: How fan isolation and identification jointly shape sponsorship performance. Journal of Marketing 82 (6): 28-48.

Meek, S., M. Ogilvie, C. Lambert, and M.M. Ryan. 2019. Contextualising social capital in online brand communities. Journal of Brand Management 26: 426-444.

Mick, D.G. 2006. Presidential address: Meaning and mattering through transformative consumer research. In Advances in consumer research, vol. 33, ed. C. Pechmann, and L. Price, 1-4. Duluth, MN: Association for Consumer Research.

Millán, A., and E. Díaz. 2014. Analysis of consumers' response to brand community integration and brand identification. Journal of Brand Management 21: 254-272.

Miller, L.E., and K.L. Smith. 1983. Handling nonresponse issues. Journal of Extension 21 (5): 45-50.
Mingione, M., M. Cristofaro, and D. Mondi. 2020. 'If I give you my emotion, what do I get?' Conceptualizing and measuring the co-created emotional value of the brand. Journal of Business Research 109: 310-320.

Mingione, M., and L. Leoni. 2020. Blurring B2C and B2B boundaries: corporate brand value co-creation in B2B2C markets. Journal of Marketing Management 36 (1-2): 72-99.

Muñiz, A.M., and T.C. O'Guinn. 2001. Brand community. Journal of Consumer Research 27 (4): 412-432.

Mogilner, C., J. Aaker, and S.D. Kamvar. 2012. How happiness affects choice. Journal of Consumer Research 39: 429-443.

Muret, D. 2016. Plazas take the party to the front porch. Sport Business Daily. Retrieved from https://www.sportsbusinessdaily.com/Journ al/Issues/2016/02/08/In-Depth/Plazas.aspx.

Nahapiet, J., and S. Ghoshal. 1998. Social capital, intellectual capital, and the organizational advantage. Academy of Management Review 23: 242-266.

Nicolao, L., J.R. Irwin, and J.K. Goodman. 2009. Happiness for sale: Do experiential purchases make consumers happier than material purchases? Journal of Consumer Research 36: 188-198.

Oliver, R.L. 1999. Whence consumer loyalty? Journal of Marketing 63 (5): 33-44.

Pansari, A., and V. Kumar. 2017. Customer engagement: The construct, antecedents, and consequences. Journal of the Academy of Marketing Science 45: 294-311.

Pine, B.J., and J.H. Gilmore. 1998. Welcome to the experience economy. Harvard Business Review 76: 97-105.

Popp, B., and H. Woratschek. 2017. Consumer-brand identification revisited: An integrative framework of brand identification, customer satisfaction, and price image and their role for brand loyalty and word of mouth. Journal of Brand Management 24: 250-270.

Preacher, K.J., and A.F. Hayes. 2008. Asymptotic and resampling strategies for assessing and comparing indirect effects in multiple mediator models. Behavior Research Methods 40: 879-891.

Putnam, R.D. 2000. Bowling alone: The collapse and revival of American community. New York, NY: Simon \& Schuster.

Ryan, R.M., and E.L. Deci. 2000. Self-determination theory and the facilitation of intrinsic motivation, social development, and wellbeing. American Psychologist 55: 68-78.

Ryan, R.M., and E.L. Deci. 2001. On happiness and human potentials: A review of research on hedonic and eudaimonic well-being. Annual Review of Psychology 52: 141-166.

Schau, H.J., A.M. Muñiz, and E.J. Arnold. 2009. How brand community practices create value. Journal of Marketing 73 (5): 30-51.

Schmitt, B., J.J. Brakus, and L. Zarantonello. 2015. From experiential psychology to consumer experience. Journal of Consumer Psychology 25 (1): 166-171.

Schnebelen, S., and M. Bruhn. 2018. An appraisal framework of the determinants and consequences of brand happiness. Psychology \& Marketing 35: 101-119.

Sheth, J.N., N.K. Sethia, and S. Srinivas. 2011. Mindful consumption: A customer-centric approach to sustainability. Journal of the Academy of Marketing Science 39: 21-39.

Seiders, K., G.B. Voss, D. Grewal, and A.L. Godfrey. 2005. Do satisfied customers buy more? Examining moderating influences in a retailing context. Journal of Marketing 69 (4): 26-43.

Stokburger-Sauer, N., S. Ratneshwar, and S. Sen. 2014. Drivers of consumer-brand identification. International Journal of Research in Marketing 29: 406-418.

Swaminathan, V., A. Sorescu, J.B.E.M. Steenkamp, T.C.G. O'Guinn, and B. Schmitt. 2020. Branding in a hyperconnected world: Refocusing theories and rethinking boundaries. Journal of Marketing 84 (2): 24-46.

Torres, P., M. Augusto, and E. Wallace. 2018. Improving consumers' willingness to pay using social media activities. Journal of Services Marketing 32 (7): 880-896. 
Tsai, W., and S. Ghoshal. 1998. Social capital and value creation: The role of intrafirm networks. Academy of Management Journal 41 (4): 464-476.

Van Boven, L., and T. Gilovich. 2003. To do or to have? That is the question. Journal of Personality and Social Psychology 85 (6): $1193-1202$.

Whetten, D.A. 1989. What constitutes a theoretical contribution? Academy of Management Review 14 (4): 490-495.

Wolter, J., and J.J. Cronin. 2016. Re-conceptualizing cognitive and affective customer-company identification: the role of selfmotives and different customer-based outcomes. Journal of the Academy of Marketing Science 44 (3): 397-413.

Yoshida, M. 2017. Consumer experience quality: A review and extension of the sport management literature. Sport Management Review 10: 427-442.

Yoshida, M., B. Heere, and B.S. Gordon. 2015. Predicting behavioral loyalty through community: Why other fans are more important than our own intentions, our satisfaction, and the team itself. Journal of Sport Management 29 (3): 318-333.

Zeithaml, V.A., L.L. Berry, and A. Parasuraman. 1996. The behavioral consequences of service quality. Journal of Marketing 60 (2): $31-46$.

Zhong, J.Y., and V.W. Mitchell. 2010. A mechanism model of the effect of hedonic product consumption on well-being. Journal of Consumer Psychology 20: 152-162.

Zhong, J.Y., and V.W. Mitchell. 2013. Does consumer well-being affect hedonic consumption? Psychology \& Marketing 29 (8): 583-594.

Publisher's Note Springer Nature remains neutral with regard to jurisdictional claims in published maps and institutional affiliations.
Masayuki Yoshida is an Associate Professor of sport management in the Department of Sports and Health Studies at Hosei University, Japan (Email: masayoshida@hosei.ac.jp). His research interests include consumer psychology and behavior from a sport marketing perspective. His research has been published in academic journals such as Corporate Reputation Review, Electronic Commerce Research and Applications, Leisure Studies, Group Dynamics: Theory, Research, and Practice, Journal of Sport Management, Sport Management Review, and Sport Marketing Quarterly.

Brain S. Gordon is an Associate Professor of sport management in the Department of Health, Sport, and Exercise Sciences at the University of Kansas (Email: bsgordon@ku.edu). His research interests include brand management, retro marketing, and consumer behavior/psychology. His research has been published in academic journals such as Corporate Reputation Review, Electronic Commerce Research and Applications, Journal of Sport Management, Sport Management Review, and Sport Marketing Quarterly.

Jeffrey D. James is a Professor of sport management in the Department of Sport Management at Florida State University (Email: jdjames@ fsu.edu). His research interests include sport consumer psychology, sport consumer behavior, and sport sponsorship. His research has been published in academic journals such as the Journal of Business Ethics, Managing Service Quality, Leisure Sciences, Journal of Sport Management, Sport Management Review, and Sport Marketing Quarterly. 